Knowledge work in nursing and midwifery: an evaluation through computer mediated communication

Published in Brooks, F. and P. Scott, Knowledge work in nursing and midwifery: an evaluation through computer mediated communication. International Journal of Nursing Studies, 2006. 43: p. 83-97.

Fiona Brooks BA, PhD

Professor, Centre For Research In Primary and Community Care, University of Hertfordshire

Peter Scott BA, PhD

Head of the Centre for New Media, Knowledge Media Institute, The Open

University. Milton Keynes, MK7 6AA.

Address for Correspondence:

Dr Fiona Brooks

Reader In Primary Health Care

CRIPPAC

Wright Building

Hatfield Campus

University of Hertfordshire, UK

f.m.brooks@herts.ac.uk

Phone 01707285994

Fax 01707285995 


\title{
Knowledge work in nursing and midwifery: an evaluation through computer mediated communication
}

\author{
Abstract (112 words) \\ Recent changes in policy and culture require health workers to incorporate \\ 'knowledge work' as a routine component of professional practice. Innovative \\ computer-mediated communication technologies provide the opportunity to evaluate \\ the nature of knowledge work within nursing and midwifery. This study embedded an \\ online discussion system into an acute NHS Trust to support interaction within \\ communities of practice. The complete record of online communications was \\ analysed. \\ Nurses were found to predominantly engage in information work with knowledge \\ work restricted to senior-to-senior level exchanges. In contrast, midwives were \\ observed to employ the technology to support knowledge work between all grades. \\ The study indicates that technology can support knowledge work, including \\ conveying tacit knowledge effectively.
}

\section{Key words: (5)}

Knowledge work, nursing informatics, professional communication, national service frameworks, computer-mediated communication. 


\section{Introduction}

Within health care systems the hierarchical, task-focused, protocol driven model of nursing organisation has been systematically criticised for bringing into question the future contribution of the profession (Spitzer, 1998). In the UK, increasing the participation of frontline nursing and midwifery staff within the policy-making, planning and decision-making of their organisation appears as a recurring priority throughout the NHS modernisation agenda (Department of Health, 1999, Department of Health, 2000, Department of Health, 2001). This priority has been reinforced through the modernisation agency's remit to establish routes for the capture and dissemination of knowledge and 'know how'. In policy terms, for nursing and midwifery a direct link has for some time been made between enhanced clinical performance and the development of more open and efficient communication systems (Department of Health, 1999). The overall result of the UK modernisation agenda is that front-line nurses and midwives are increasingly being expected to function not only as 'information workers'; the passive consumers of work related knowledge, but also as knowledge workers; active producers and managers of professional knowledge.

\subsection{Nursing and knowledge work}

Despite the policy demand for a move towards professionals' functioning as knowledge workers, the application of the concepts of knowledge management theory to the UK health system and nursing in particular, represents a relatively new phenomenon (Antrobus, 1997). Knowledge management theory asserts that the strength of any organisation lies in the knowledge of that organisation's people. The idea is that organizations with effective knowledge management processes are able to expand and improve their professional knowledge base, by capturing and sharing the experience of key staff. This knowledge enables organisations and professionals to respond to change by providing a structure to assimilating new knowledge from staff experiences (Quintas, 2002). By problematizing knowledge as both distinct from information and something that must be effectively communicated within organisations, knowledge management theory may offer a means for nursing to begin to conceptualise new communication structures (Szulanski, 2000).

In knowledge management theory many workers within an organisation simply act as passive consumers of information that directs their actions. These are 'information workers' and the knowledge they consume is entirely explicit and clear. In contrast, 'knowledge workers' are those who are able to critically reflect upon the explicit knowledge of the organisation by adding personal, theoretical and tacit knowledge 
acquired from their own experience. In nursing, effective knowledge work is therefore likely be dependant on the combination of a situated, reflective and experiential or a tacit knowledge base gained through clinical practice with scientific or intellectual knowledge (Antrobus 1997, Titchen and Ersser, 2001). Here an important distinction needs to be made between explicit formalised knowledge for example, organisational rules that can be simply codified and do not require discussion to be implemented (Bate and Robert, 2002) and the experiential, problem solving elements (or "know what" and "know how") of tacit knowledge that become developed and refined through the process of engagement with others (RycroftMalone et al., 2004). In social constructionist theories of knowledge management (Bate and Robert, 2002, McAdam and Reid, 2001) knowledge transfer is defined as the communication of tacit knowledge. Communication of such experiential, problem-solving knowledge is essential if the tacit knowledge held by individuals is to become actionable and operational within their larger community and organisation. Knowledge is not only held by individuals, but is both produced and held collectively by groups of people working together in a community of practice, to achieve a shared understanding (Lave and Wenger, 1993, Seeley-Brown and Duguid, 1991) The transformation of frontline nursing and midwifery staff into knowledge workers will be dependant on the following three key developments within health service organisations and patterns of communication within professional cultures:

a) Structures that allow the diffusion of critical information to the individual professional will have to be developed. Information systems will need to become 'primarily person based rather than organization-based' (Department of Health, 1998).

b) Individuals must also be able to use new information to act as 'critical reflective thinkers' (Schon, 1987), that is be able to generate new knowledge from their experiences and importantly identify how that knowledge can be translated into changes in practice (Brockbank and McGill, 1998).

c) Finally to participate in decision-making nursing will need communication channels that enable knowledge transfer of tacit knowledge not just explicit knowledge. Consequently the individual nurse or midwives' interpretation of and response to information will need to be shared with colleagues and diffused throughout the organisation. This implies an ability to employ modes of communication with colleagues that facilitate discussion, feedback and action. This communication allows the synergistic potential of nurses and 
midwives collaborations to produce new and refined knowledge to improve the delivery of care.

The application of knowledge management theory to nursing immediately highlights a number of tensions for the profession in any attempt to embed knowledge work as a routine component of nursing and midwifery practice. The hierarchical structures of the profession and the ambivalent position of nursing and midwifery in the health care division of labour represent barriers to the development of broad-based and discursive patterns of communication (Spitzer, 1998). In particular, it has been observed that nursing appears to have an underdeveloped appreciation of how to make use of and communicate nurses' tacit knowledge in order to influence policy and practice (Antrobus 1997). This leaves frontline nurses in an isolated position without access to the synergistic potential of their community of practice and thereby a means to translate their experiences into new knowledge and action. This position may in part account for nurses' resistance to engagement with other forms of knowledge that require a critical engagement, including intellectual knowledge (Royle et al., 2000) and for a passive, non-critical response to policy-making, (Cheek and Gibson, 1997). Logistical barriers may also prevent connection with a community of practice, as in most health care organisations the nursing workforce is spatially isolated within wards (Halford and Leonard, 2003), time constrained and increasingly part-time.

Significant recent conceptual contributions that highlighted the determinants constructing the development of evidence based practice in nursing (McCormack et al., 2002, Rycroft-Malone et al., 2004). However, there is an opportunity for empirical studies to provide evidence on how knowledge work more broadly might actually be displayed and measured in nursing and midwifery. Moreover, research on knowledge work in midwifery, as distinct from nursing, has been somewhat overlooked. Research on the location of midwifery in the health service does however suggest that despite being described as autonomous practitioners, midwife innovators, (potential knowledge workers) may also be marginalised within current structures (Hughes et al., 2002, Kirkham, 1999).

Existing research highlights a real challenge for nursing in the transition to becoming knowledge workers. Potentially the greatest value knowledge management theory can offer to nursing is that it may enable an understanding of the critical value to nursing and midwifery practice of developing effective communication structures. In the case of nursing it appears a solution needs to be found to address both the practical and the professional cultural barriers to achieving knowledge transfer. 


\subsection{Computer mediated communication in nursing and midwifery}

Effectively managed information systems have been identified as an essential prerequisite for a knowledge-based health care system (Rowland and Harris, 1998). Consequently, a possible solution to the health care 'communication and information gap' for nursing may lie in the development and application of new Information and Communication Technologies (ICT's), (Department of Health, 1999, Lacja, 1999, Nauert, 1997, Wyatt, 2001). Empirical support for the potentially positive role of new ICT's has been found in educational and business settings where computer mediated communication has enhanced the sharing of ideas and collaborative thinking (Ruberg et al., 1996), enabling staff to successfully participate in decision-making processes (Bishop and Levine, 1999). Among geographically isolated staff, computer mediated discussion groups have also enabled staff to access a wider community of practitioners and draw on a greater reserve of expertise and knowledge (Hightower and Sayeed, 1996).

Local and professional culture in which a technology is embedded is also a key determinant in successful implementation (Heath et al., 2003). Studies concerned with attitudes to computers and tools, such as the internet, suggest that nurses' professional use and acceptance of the value of computers to their professional practice is lower than for other professional communities (Kaplan, 2000, Timmons and Tredoux, 2000). Nursing, it seems, not only suffers from an absence of appropriate systems targeted to meet their professional needs, but barriers of time, access, workload and attitude may also prevent nurses from embracing computer use as a medium for knowledge work and knowledge transfer (Estabrooks et al., 2003, Royle et al., 2000). When nursing computer usage has been analysed by type of system, there is evidence that nurses exhibit strong preferences for computer mediated communication systems that are interactive and supports collegial communication (such as email), over purely information resources (such as the internet, see for example, Estabrooks et al., 2003, Pereira et al., 2001). Use of interactive computer mediated communication systems in educational contexts by nurses has been found to facilitate critical reflective thinking that questioned traditional nursing discourses and generated suggestions for improvements in practice (Murray, 2003, Murray, 1996). Among midwives there have been relatively fewer studies (Brooks et al., 2004), but new ICT's use has been found to enhance audits of practice and promote access to evidence (Betts and Washbrook, 1995, Littler and Weist, 1998). 
Outside educational settings, less empirical attention has been given to investigating how interactive, computer mediated communication might impact on nurses and midwives interaction patterns. In particular, a number of questions remain concerning the functioning of such systems, in either the naturalistic settings of a health care organisation, such as a hospital trust, or the potential of computer based communication systems in routine ward contexts to engage frontline nursing and midwifery staff. More significantly, the nature of nursing and midwifery interaction and communication that occurs in participative computer mediated systems and the degree or character of knowledge sharing that might occur remains unexplored.

\subsection{The Assisted Electronic Communication Project}

This paper reports findings from the Assisted Electronic Communication (AEC) project, which sought to enable nurses and midwives to incorporate knowledge work into their daily practice through use of computer mediated communication technologies. The project prototyped, implemented and evaluated an online discussion forum linked to policy documents and designed specifically for nurses and midwives. It was intended that the technology-assisted discussion forums could be used to stimulate change or innovation in practice without staff ever leaving the ward. The forums provided a means for a previously paper based document to be linked directly to a public discussion space. This enabled nurses and midwives to send views, ideas and responses directly and electronically, to other practitioners. All the messages were available to be either read or responded to by anyone accessing the system. Contributions from participants were posted as asynchronous messages, which were threaded with the additional facility of linking the discussion with sections of the document. Threading is a technical device that enables users to track and cluster specific topics within the larger discussion, via the titles of submitted messages. The system was entirely web-browser based with users clicking through web pages and submitting forms in all interactions.

The project was located in an acute hospital Trust in central England and the first forums were initially implemented with a discrete group of 100 nursing staff in 4 localities, supported by the provision of dedicated machines. The initial locations were: Accident and Emergency, the Coronary Care Unit, a medical assessment unit and a general medical ward. Access was subsequently expanded to all nursing and midwifery staff via the hospital intranet.

Prior to implementation of the system an operational group of trust nursing and midwifery staff trialled the system and identified aspects that they required to be redesigned. A priority was to establish a 'user friendly' system that was responsive to 
professional needs and importantly did not distract participants from communicating by it's own internal mechanics (Fennessy, 1999, Hiltz and Johnson, 1989).

Heavily embedded into the definition of 'user friendliness of the system' constructed by the nurses, was the notion that usage of the system should not be dependent upon any time consuming, 'off ward' or formal training as this would result in the system being problematic to implement. Consequently the discussion forums were designed so that even staff who lacked basic computer competencies (such as sending an email attachment) would be able to participate on the forum, after a short 5 minute demonstration by a colleague. Moreover, it has been suggested that for nurses and midwives 'hands on approach training' in the locality is likely to enable skill retention and transfer to a critical mass of peers (Webster and Davies, 2003). The choice of documents to be linked onto the forums was made by the nursing and midwifery staff involved on the operational groups for the project. Six initial forums were established. Three were concerned National Service Frameworks (NSF) for 'Coronary Heart Disease' (CHD), 'Mental Health Services' and 'Older People'; plus three further forums which were linked to local reports on patient satisfaction: concerned with 'Obstetrics', 'Trauma and Orthopaedics' and 'Surgery'. The latter two forums were nursing-specific local documents akin to the Obstetrics (Midwifery) forum, but evinced little activity (Scott et al, 2004). In order to explore how the participants displayed knowledge work via their use of the forums for information and knowledge work the paper focuses on a detailed examination on the three major forums (each with over 50 messages): two exclusively nursing forums ( $\mathrm{CHD}$ and older people) and the entirely midwifery-led forum (obstetric forum ${ }^{1}$ ). The NSF's and patient surveys were chosen because both required detailed attention to be given to local implementation and because they addressed clinical issues involving staff from across a number of discrete locations/teams and had a direct and unambiguous relevance to patient care.

The main aim of this paper is to explore the forms of communication that occurred on the forums against the transformation criteria for knowledge work in nursing identified previously, with particular emphasis on the types of knowledge displayed and communicated. Attention is then given to exploring if discursive discussion, feedback and action occur. Finally we will focus on a critical discussion of the implications of the findings for the development of knowledge work and knowledge transfer in

\footnotetext{
${ }^{1}$ The forum was termed 'obstetric' by the hospital as the primary document covered consultant care - however the forum was used exclusively by midwives.
} 
nursing and midwifery. Consideration is given to the extent of knowledge work and the factors that serve to prevent individual nurses actively seeking the role of knowledge worker within their community of practice.

\section{Methodology}

The evaluation methodology was designed to consider the totality of the online communication for the duration of the forums operation. One of the methodological strengths of on-line data is that the researcher is a distant non-visible presence and has access to interaction that occurs naturally and in situ. All digital participation from all the forums was logged. In-depth semi-structured interviews (30 nurse users and non-user interviews; 12 midwife participant interviews) and two focus groups with operational team members were undertaken to assess experiences and views on the system. Two members of the research team, using a grounded theory approach via Atlas.ti, coded the interviews and digital participation for inter-rater reliability.

\subsection{An Analysis Framework for Information Work and Knowledge Work}

Research analysing computer mediated communication has tended to focus on a number of linguistic aspects of computer mediated communication such as flaming, spamming and acronyms (Herring, 1996). For this project we focused on two core characteristics of the medium. Firstly, we aimed to explore the nature of the discussion, including the character of the communication and knowledge displayed via the contributions to the forum. Secondly, we aimed to measure the quality of the 'knowledge work' in terms of any evidence of the impact of the forums on (a) community formation, (b) professional culture and (c) on the delivery and organisation of care. To this end we developed a 12-category framework, which we used to code the corpus of evidence provided by the discussion forums into work displaying knowledge or work displaying information.

Supporting this coding distinction is an argument about the character of knowledge work as displayed via decision-making interactions (Condon and Cech, 1996). In coding forum messages particular attention was given to the presence or absence of critical reflective thinking as a measure of knowledge work (Schon, 1987). In our framework, critical reflective thinking is coded as the display of an ability to employ experience in a manner that openly reflects upon current care and service provision. The definition of critical reflective thinking also encompassed a willingness to generate new knowledge and articulate alternative forms of provision and suggest 
ideas for the resolution of issues (Brockbank and McGill, 1998). In this way we assert that critical reflective thinking is the key to measuring displays of knowledge that is created and shared in a working context. The display of knowledge work in the forums was divided into 6 categories.

1. Discursive issue-raising. The presentation of an issue that demonstrated reflection on practice, an organisational or professional issue and that invited further debate and engagement by the community of practice, (e.g. "How can we improve on our information leaflets?").

2. Discursive debate. The communication and discussion of an issue that conveyed either differing views points or raising challenging perspectives that invited and accepted that further discussion was necessary, but did not include an articulation of alternative forms of provision, (e.g. See figure 5).

3. Discursive support. Supporting comments could be critically reflective where they presented agreement with a previous author, but also provided additional support and knowledge aiming to further the discussion, (e.g. See figure 8).

4. Discursive resolution. These messages were coded as those displaying problem-solving abilities in the form of ideas or suggested actions to create change in addition to critical reflective thinking (e.g "I think we need a working party to look at this. How about ...").

5. Tacit and evidence display. Messages that displayed the fusion of scientific or evidence-based knowledge with tacit knowledge, (e.g. "I have the new NICE guidelines, but they may be problematic, because in my experience ...”).

6. Narrative display only. This coding was assigned to story-telling in a single message without any additional discussion or other aspect of critical reflective thinking. This simple form of narrative display was placed in the knowledge work part of the framework because a message that only displayed a practice narrative could still be a form of reflection aimed implicitly to generate further knowledge work responses, (e.g. "When I was on the ward yesterday ..."). Information work and the expression of explicit knowledge was also coded into a further 6 basic categories:

1. Closed questions or requests for explicit knowledge, (e.g. information requests relating to local or national policy).

2. Display of local explicit knowledge as an answer to a discursive question, (e.g. detailing contents or location of a protocol or decision). 
3. Display of local explicit knowledge as an answer to a closed question, (e.g. detailing contents or location of a protocol or decision).

4. Display of explicit scientific or evidence based knowledge. Messages that referred to evidence practice but did not discuss implications or combine with any aspect of critical reflective thinking, (e.g. "The new NICE guidelines are available - see me").

5. Information display only. Posting of 'message board' information, (e.g. "I am running a training day on ...").

6. Non-discursive simple responses, messages that were single statements, (e.g. 'Thanks' or 'I agree').

Finally, a small number of messages were excluded from this 12-category framework. For example, a couple of exchanges in each corpus dealt with admin, joking or non-discursive agreement (such as 'I agree'). The excluded messages amounted in total to no more than 2 messages per forum.

\section{Analysis}

\subsection{Participants}

Tables 1-3, present the range of authors across the forums. As tables 1 and 2 clearly indicate the notable feature of the two nursing forums was the levels and patterns of participation from senior or more experienced staff. Table 2 shows indeed that senior use dominated the character of participation on the Older People forum. Although the $\mathrm{CHD}$ forum attracted participation from the range of nursing grades, the highest number of postings was from those of sister or charge nurse grade.

In contrast, as table 3 indicates the Obstetric forum achieved broad-based participation and included all grades of midwives. Community midwives came into the hospital on several occasions specifically in order to make contributions to the forum, despite the fact that issues of participation and linkage with primary health care staff was not within the remit of this project and no explicit attempt had been made to facilitate their participation.

\section{$<$ Tables 1-3 about here>}

At the time of this analysis, the CHD forum had been in operation for 15 months. In that time it had 26 contributors who posted 71 messages in 21 threads. The Older People forum lasted for about half that time (7.5 months) and had 11 contributors 
who posted 18 messages in 6 main threads of discussion. The Obstetric forum had been in operation for only 1.5 months at the time of this analysis. In that short time it had 29 contributors who posted 70 messages in 11 threads.

\subsection{Analysis by category}

<Figure 1 about here>

Figure 1 shows a broad category summary of information and knowledge work that were found in the 3 major forums. It might be expected that differences in the communication measured may be due to the local or national provenance of the documents. This does not seem to be the case. Overall, for nursing contributors most of the CHD National Service Framework forum could be coded as information work and most of the Older People National Service Framework forum was coded as more discursive and critically reflective, knowledge work. The midwives' Obstetric forum was overwhelmingly coded as knowledge work.

The detailed breakdown of the coding summarized in figure 1 is shown in the two figures 2 and 3 . Each type of knowledge has been coded into the 6 information and 6 knowledge categories discussed above.

\section{$<$ Figures 2-3 about here>}

In both figures column 4 shows the forum messages that can be considered to have some elements of evidence-based practice. There were very few messages in any of the forums that could be coded as evidence-based exchanges. In figure 2 this represents the discursive use of evidence, (a small number in the midwifery obstetric forum) whilst in figure 3 it represents explicit scientific or evidence based messages (a small number in the nursing CHD forum).

The striking feature of the nursing $\mathrm{CHD}$ forum in figure 3 is the dominance of categories which respectively represent closed questions and explicit knowledge presented in response to a closed question (see columns 1 and 3). In contrast, a significant feature of the midwifery obstetric forum in figure 2 is the dominance of exchanges coded as discursive resolution (see figure 2, column 6).

Critical reflective thinking characterised the majority (75\% of messages) on the older people forum. On the Obstetric forum $93 \%$ of messages were coded as discursive in one form or another. Across all the forums (including the orthopaedics and surgery 
forums) generally comparable numbers of messages consisted of discursive issueraising. However, the levels and types of responses to this issue raising was found to be markedly different across the forums, for example, in the obstetric forum $43 \%$ of the total messages could be categorised as containing discursive resolution where such messages accounted for only $7 \%$ of the CHD forum. The messages on the $\mathrm{CHD}$ forum stand in marked contrast to the other forums with only $30 \%(n=21)$ of messages on this forum demonstrating any of the criteria for critical reflective thinking. Moreover, when broken down the majority of discursive contributions on the $\mathrm{CHD}$ forum (14\% of forum messages) consisted of the initial raising of an issue that invited debate, but predominantly remained unanswered. In contrast, in the midwifery-led forum a comparable number of initial discursive questions/issues (16\% of forum messages) generated a further 30 (45\% of messages) postings which could be coded as discursive resolution, compared to only 5 such messages $(7 \%)$ in the CHD forum. The contrast in the levels of discursive debate, support and discursive resolution reflected markedly different forms of communicative work being displayed by groups of participants.

\subsection{Doing Information work}

The CHD forum functioned primarily as a practically focused information resource whose pattern of contributions reflected predominantly information work, in the form of a question and answer format. For example, 17 of the 21 threads were initially posted by staff nurses requesting answers to very focused factual information, either on the details of the NSF, or on specific details of how local implementation would occur. In the majority of cases (16 of the 17 threads $24 \%$ of all messages on the forum) initial questions received a complete factual answer from senior staff or from the local nurse NSF co-ordinator. Longer discussion threads consisted of further elaborations of the answer from the same or another 'answering member of staff.' The following example represents a typical exchange on the $\mathrm{CHD}$ forum.

\section{$<$ Figure 4 about here>}

Much of the knowledge displayed on this forum was concerned with describing the service as is currently provided. Predominantly the exchanges $(70 \%$ of the messages) between nurses on the $\mathrm{CHD}$ forum were concerned with the communication of information relating to rules, already established policies and 
protocols. Questions posted on the forum by staff were primarily focused on the exchange of information about the location of policies and protocols ( $31 \%$ of messages). Moreover, the presentation of explicit knowledge frequently ended the discussion on a topic with no further postings (see example figure 4) rather than facilitating further debate. In contrast on the obstetric forum similar statements concerning the existence of protocols or information were found to prompt further responses and discussion. In the example thread shown in figure 5, a further 8 messages were posted leading to the setting up of a working party to develop new information leaflets for women.

$<$ Figure 5 about here $>$

In general, it was forms of explicit knowledge that were prioritised by the nurses on the CHD forum as the knowledge to be shared and engaged with by their network. Only three messages contained knowledge relating to evidence based practice or research evidence. Instead, the messages demonstrated a strong preference for requesting and supplying locally derived and constructed explicit knowledge. Significantly, the forms of explicit knowledge displayed in the forums were by definition forms that could be exchanged without the need for discursive discussion (Wyatt, 2001). A low level of presentation or engagement with evidence-based explicit knowledge was a consistent feature of the all the forums. Replies employing evidence based knowledge accounted for only 7 messages out of the total 195 messages across the three forums. While a reflective approaching combining evidence and tacit knowledge was found only on the obstetric forum in 4 of the 7 messages.

In contrast to the CHD forum, the remaining forums (that attracted good participation rates) displayed much lower levels of information seeking and presentation of local explicit knowledge. For example, in the older people forum only 6 messages were posted requesting explicit knowledge, whilst the obstetric forum did not contain any such messages. Instead, the messages on the obstetric and older people forums displayed more critical reflective thinking and engagement with tacit knowledge.

\subsection{Tacit knowledge and critical reflective thinking}

Effective knowledge management work is also dependent on the sharing of tacit knowledge across the organisation and within communities of practice. In the case of 
the CHD forum postings that offered the opportunity to the display of tacit knowledge, such as questions that requested a discussion relating to service development or organisational change, (below figure 6: How can we improve to meet the targets?) in the majority of cases remained unanswered.

$<$ Figure 6 about here>

In contrast, the messages on the Older People and Obstetric forums were primarily concerned with discursive and supportive debate of either local implementation or of issues relating to the organisation of care. In the Older People forum, 2 of the 13 main discussion threads contained evidence of extensive and in-depth critical reflective thinking, concerning how to improve service provision in relation to falls and how to address age discrimination (see figure 7).

$<$ Figure 7 about here>

\subsection{Discursive Issue Raising}

As noted above in the midwifery-led obstetric forum instances of discursive and supportive discussion were found to dominate the messages posted on the forum. Critical perspectives that related to the strategic levels of decision-making and the need for a re-organisation of current forms of service delivery both locally and nationally within the midwifery profession were routinely conveyed in all the threads. In particular the identification of ways to develop a more patient centred service was found in all the threads on this forum. In seven of the threads discussion was focused on how to develop local services such as new information leaflets or the modification of the local policies concerning organisation of services such as the rules relating to visitors. However, discursive debate and support in three of the threads enabled staff to display their tacit knowledge drawn from practice, to debate issues relating to the philosophy and nature of midwifery care rather than solely focus on immediate local activity. Figure 8 shows an example from the thread on "Labour needs".

$<$ Figure 8 about here> 
One of the concerns with public discussion and display of tacit knowledge is the potential for conflict or dirty linen washing. Evidence from the online discussion suggests that such a concern may in reality prove unfounded. Throughout all the forums angry 'venting' occurred in only one of the threads, this immediately resulted in members of the forum sending two 'policing' messages intended to reorient the discussion back to constructive debate. In the remaining overwhelming majority of cases the contribution to the discussion developed and extended contributions from other staff in a supportive manner.

Overall, in both the older people forums and obstetric forum the participating staff were observed to convey their personal tacit knowledge to effectively create dialogue within their own community of practice.

\subsection{Impacts of the System}

Display and communication of tacit knowledge is only one component of the knowledge worker an effective knowledge worker is able to process dialogue from their community of practice in order to generate new knowledge and create positive change.

In the CHD forum, which was largely coded as 'information work', such as questionand-answer interactions on details of the NSF, the main impact of the system was perceived to be increased knowledge of the content of the NSF with, for example, interview respondents reporting that looking at the system (even if they had not posted a message - 17 respondents) had increased their understanding of the purpose of the National Service Framework.

"NSF easy to read, easy to pick up areas you needed to know. Interesting to see what other people thought."

In terms of the linked on-line discussion, the simple physical visibility of other professionals' postings 'to see other people's opinions' (Staff nurse A\&E) was particularly valued. Some peripheral participation, also commonly referred to as 'lurking' (Lave and Wenger, 1993) appears among the respondents to been seen as a legitimate activity. In this paper, we are reviewing the overt displays of information and knowledge work, and so have not considered covert forms of work (such as lurking) which we have discussed elsewhere (Scott et al., 2004). However, it is the application of critical reflective thinking within a discussion and action cycle that indicates recognition of responsibility for the development of care and involvement in decision-making. The online encounters on the CHD forum did 
not display any evidence of a move towards the creation of new knowledge that could lead to service change.

Both the older people and the obstetric forums displayed evidence of moving the discursive discussion into achieving action and change. However, it should be noted that identification of the exact extent of final resolution of issues raised on the forums is problematic, simply because ultimately the majority of issues will be practically resolved off-line. In the obstetric forum 30 contributions (in nine threads) and in the older people forum 10 contributions (in eight threads) contained a suggested means to achieve a resolution of an issue. The following forms of resolution were identified as occurring:

- Direct resolution on-line, usually with a senior manager agreeing to a change in provision and allocating resources. For example, senior midwifery managers allocated specific resources in two of the threads (three contributions), with the result that, for instance, fans were installed on labour ward.

- Working parties, or off-line groups were explicitly suggested in four contributions so that staff could physically meet and resolve the issue. This form of resolution was usually directly linked to an on-line discussion of the need to develop new strategies or policies such as the development of a falls policy for older people or to develop a new information leaflet.

- Sharing of tacit knowledge and creative ideas to improve a specific issue.

\section{The construction of knowledge workers}

The findings demonstrate a difference in the levels and character of engagement with knowledge work between midwifery and general nursing. Although the project did not set out to provide a focused exploration of the difference between professional cultures, the findings do indicate some of the core issues preventing nurses from functioning as critical reflective practitioners. In the case of midwifery usage of the discourse forums also demonstrates the value of engaging with knowledge work when such barriers are overcome. Among the general nursing staff who were interviewed, techno-fear or fear of 'come-back' did not feature in the accounts as reasons for structuring the character of participation. Instead, respondents suggested that for nurses, engagement in broader health policy and quality improvement issues were not perceived as an integral or essential component of their work. Moreover, communication with other professionals or even discussion 
within a community of nursing did not have a high level priority. In contrast the focus of nursing staff was solely on tasks associated with immediate and direct care. In addition in a situation where the main purpose of engagement with colleagues is viewed to be information work then participating with the forum becomes irrelevant if individuals perceive they do not have any information needs, as the following staff nurse illustrates:
Q: Did you find helpful having the NSF on the site?
"I think it would be good for staff that had no idea about the national health, you know that may ask questions from people that do. But I think, in general, nurses tend to concentrate on the area that they're interested in and the patients that they're working on. And so I never really saw any use that I could make of it." (Staff nurse, coronary care)

Similar findings have been found by others, for instance, (Larsen et al., 2002) identified that nurses in clinical practice relied little on the research knowledge, but instead personal tacit knowledge and immediate colleagues provided the 'relevant context' for managing their clinical tasks. However, a study of multi-professional team working (Cott, 2000) indicated that the structural position of nursing resulted in an approach to team work that was problematic in so far as it focused only on direct care, and importantly excluded notions of improving the quality of the work. Equally, it appears from this study that an exclusive focus on immediate task orientated care impacts negatively on the levels of engagement in general nursing with policy changes and on the degree of commitment to have a voice in the decision-making process.

\section{Q: Do you see updating and communicating that knowledge as part of your role?}

"No. No, I don't. Because - it's not nursing, you know. Nursing is dealing with a patient." (Senior nurse, non-user)

Moreover, engagement with a broader multidisciplinary team was viewed with ambivalence, as it was "not essential to helping them complete their work tasks." (Cott, 2000). Not only was there evidence that a task-focused orientation dominated the perspectives of many of the nurses, but that there was a belief that engaging with a community of practice would have limited impact and value.

"Discussion is just words. It doesn't bring in the resources that are needed to actually implement these things." (Sister, 
accident and emergency)

'Busyness' was frequently presented by nurses as blocking engagement with updating and policy related decision-making.

"We have just been too busy, too busy." (Staff nurse, surgery)

"Don't even talk to me about it. I am too busy." (Staff nurse, trauma and orthopedics)

In the context of a 'time-pressured' working environment the construction of work priorities is likely to be highly influenced by the local cultural context. That is, what should and needs to be done will be defined by the values of manager and colleagues. Support for this contention came from interview respondents who said that contributing to practice and policy discussion was perceived by the local professional culture to occupy a low priority in the hierarchy of valued nursing tasks.

"Our colleagues [...] don't always help, I am sad to say. There was a nurse using the project the other day and a senior member of staff, who should know better looked at her and said 'hasn't she got something better to do?' That's the attitude we have to deal with." (Senior nurse, general ward)

Participants on the older people NSF forum expressed the normative expectation that knowledge work was a fundamental component of their work identity. This did not so much stem from a perception that this role was integral to nursing work per se, but rather functioning as knowledge workers was connected to their position within the organisation. As senior members of staff, experts and vertical leaders knowledge work and consequently participation on the forums was seen to be their 'remit'. Given that both the CHD forum and the Obstetric forum attracted both junior and senior members of staff as participants, influence of professional culture and the potential impact of time poverty on individuals self perception as knowledge workers was explored in detail with the midwives. A time pressured working environment was reported by the overwhelming majority of midwifery respondents. However, in marked contrast to the nursing staff, 'busyness' was not perceived by midwifery respondents to be an overriding constraint to contribution to the forum. 
"Well it would have taken me about probably about 10 minutes, but on ward you're being interrupted every 2 seconds with the door being opened and telephones and things so it did take me sort of 30/35 minutes to actually get it down properly." (Staff midwife)

Among the midwifery participants one of the strong emergent characteristics of their local culture was a link between definitions of appropriate actions for a midwife and a commitment to prioritise participation on the forum. Intrinsic to the participants' definition of midwifery practice was a normative expectation that they should undertake knowledge work.

"No, I didn't think it was time consuming, even when rushed you make the time, if you want to have a say." (Staff midwife)

In this context, the discussion forums provided a platform that enabled knowledge work to be undertaken with individual midwives 'connecting' with their community of practice.

Positive computer based communication system performance has been strongly linked to the process of contributing being perceived as a stimulating and interesting process (Hiltz and Johnson, 1989). In fact, from the majority of midwifery interview respondents there was a real sense of excitement about the project technology as a form of communication.

"It was really exciting to go in and see if any-one had added anything - I would sit there and think, I wonder what is going on now and then have to have a look." (Staff midwife)

There is also evidence that the way the system visibly organised information, by threading the contributions, had a positive impact. Being able to view the structure of an argument, the threading was perceived as enabling respondents to identify where they could contribute to the discussion.

"It's good to see what people think about things and it's an area that's a point for discussion isn't it, somebody broaches one subject then other people follow." (Senior midwife)

One of the significant impacts of the system as perceived by the midwives, was the opportunity online discussion offered to engage with a broad community of practice and overcome some of the practical barriers created by the modern organisation of work within health systems. 
"It helps you communicate with your peers that you might not necessarily see on a regular basis; but if you use it regularly it helps you communicate in a more complete way." (Staff midwife)

Overall, by providing midwives with a means to establish new relationships with colleagues based on a discursive dialogue, participation was felt to enhance their sense of a being part of a community of practice, and thereby supported community formation through enabling otherwise isolated midwives to communicate.

\section{Conclusions}

This paper set out a 12-category analysis framework to measure the display of knowledge and information work in nursing and midwifery. This display was set in the context of an online discussion system designed to support effective communication between nurses and midwives. The analysis framework was able to provide a measure of the nature of decision-making interactions by which a group of nurses and midwives communicated tacit and explicit knowledge around important documents.

The on-line discussions displayed a varied range of the characteristics of critical reflective thinking, as senior nurses and midwives openly critiqued and proposed alternative visions of care. All the forums contained high numbers of instances of discursive issue-raising and individual nurses and midwives were able to display the ability to invite engagement with their community of practice. However, our findings suggest that the willingness to engage with decision-making processes, including service and practice development varied between the nursing and midwifery professions. The online forums demonstrated a marked distinction between nursing and midwifery specialties in terms of their current capacity to communicate ideas, and their overall levels of expertise in discursive communication.

Information work and the transmission of local explicit knowledge rather than knowledge work characterised communication patterns between junior and senior nursing staff. In contrast, messages posted by midwifery staff tended to sustain horizontal on-line displays of expertise in discursive debate. Exchanges between midwives not only critiqued current provision and supportively further discussion, but also contained a relatively high number of suggested means to resolve issues. Few observed messages on any of the forums incorporated evidence-based knowledge. The limited occurrences of references to the practice evidence base in 
combination with tacit knowledge were found solely in the one forum that exhibited the most extensive amount of critical reflective thinking. This may indicate that the effective fusion of tacit knowledge and evidence-based practice is likely to be a more advanced aspect of functioning as a knowledge worker.

One of the purported strengths of online discussion is that such discussion offers a means to make physical meetings more efficient, as much of the discussion and allocation of work is likely to have occurred on-line. Among the midwives and senior nursing staff Information technology in the shape of the project technologies became the means to overcome barriers of time, by not requiring a meeting, of distance by enabling for example shift workers to communicate, and finally that of isolation and marginalisation, by enabling all grades of staff to develop a discursive community of colleagues.

Previous research identified difficulties for the NHS in sustaining horizontal networks across organisations (Bate and Robert 2002) and that local organisational context and professional cultures not only structure the use of technology (Heath et al., 2003) but can have negative implications for NHS knowledge sharing (McCormack et al., 2002). Part of the account for our findings may be located in a fundamental difference between the status, working practices and autonomy of the communities of practice, in nursing and in midwifery. This account is certainly worthy of further exploration.

Furthermore, the AEC project has highlighted that for nursing there are difficulties created by micro local professional cultures in developing effective horizontal networks within even single NHS organisations.

The AEC project has demonstrated that novel ICT can function as a powerful tool in improving effective communication between nursing and midwifery professionals (Scott et al., 2004). This study has shown that the technology can support both effective information work and knowledge work. In particular, online discussion can provide a means to convey tacit knowledge in an effective and influential manner. Overall, the project provided insights into how ICT could support the process of cultural change that seems to be required to facilitate the development of health professionals as knowledge workers. However, this is inevitably dependent on such technologies being embedded into a local organisational context and professional culture that is supportive of discursive communication.

\section{Acknowledgements}

This research was funded by the UK Department of Health, under the information and Communications Technologies Research Initiative, (121-7184). We would also 
like to thank the nursing and midwifery staff at the hospital. Many thanks also go to Christine Rospopa, Kevin Quick, Maria Macintyre, the operational group and our reviewers for the International Journal of Nursing Studies. We would also like to make special mention of the contribution to the discussion forums of Sharon Hodsdon, a true knowledge worker and midwife, a tragic loss. 


\section{References}

Antrobus, S., 1997. Developing the nurse as a knowledge worker in health: Learning the artistry of practice. Journal of Advanced Nursing 25, 829-835.

Bate, S., Robert, G., 2002. Knowledge management and communities of practice in the private sector. Lessons for modernizing the National Health Service in England and Wales. Public Administration 80 (4), 643-663.

Betts, H., Washbrook, M., 1995. How information management and technology benefit midwives. British Journal of Midwifery 3 (9), 478-482.

Bishop, L., Levine, D., 1999. Computer mediated communication as employee voice. A case study. Industrial and Labour Relations Review 52 (2), 213-233.

Brockbank, A., McGill, I., 1998. Facilitating Reflective Learning in Higher Education. Society for Research into Higher Education and The Open University.

Brooks, F., Rospopa, C., Scott, P., 2004. Midwifery on the net: new communication technology. British Journal of Midwifery 12 (2), 107-110.

Cheek, J., Gibson, T., 1997. Policy matters: Critical policy analysis and nursing. Journal of Advanced Nursing 25 (4), 668-673.

Condon, S.L., Cech, C.G., 1996. Functional comparison of face-to-face and computer-mediated decision-making interactions. In: Herring, S. (Ed.), Computer-mediated communication: Linguistic, social, and cross-cultural perspectives. John Benjamins, Philadelphia.

Cott, C., 2000. Structure and Meaning in Multiprofessional teamwork. In: Davies, C., Finlay, L., Bullman, A. (Eds.), Changing Practice in Health and Social Care. Sage Publications, London.

Department of Health, 1999. Making A Difference. HMSO, London.

Department of Health, 2000. The NHS plan: A plan for Investment a plan for reform. HMSO, London.

Department of Health, 2001. Shifting the Balance of Power within the NHS: Securing Delivery. HMSO, London.

Department of Health, 1998. Working Together: securing a quality workforce for the NHS. HMSO, London.

Estabrooks, C.A., O'Leary, K.A., Ricker, K.L., Humphrey, C.K., 2003. The internet and access to evidence: how are nurses positioned? Journal of Advanced Nursing 42 (1), 73-81.

Fennessy, G., 1999. The role of information technology in quality improvement: Has it had an impact? Health Care Quality 4 (5).

Halford, S., Leonard, P., 2003. Space and place in the construction and performance of gendered nursing identities. Journal of Advanced Nursing 42 (2), 201-208.

Heath, C., Luff, P., Svensson, M., 2003. Technology and medical practice. Sociology of Health and Illness 25, 75-96.

Herring, S., 1996. Two Variants of an Electronic Message Schema. In: Herring, S. (Ed.), Computer-Mediated Communication: Linguistic, Social and CrossCultural Perspectives. John Benjamins, Amsterdam/Philadelphia.

Hightower, R., Sayeed, L., 1996. Effects of communication mode and prediscussion information distribution characteristics on information exchange in groups. Information Systems Research 7 (4), 451-456.

Hiltz, S., Johnson, K., 1989. Measuring acceptance of computer-mediated communication systems. Journal of the American Society for Information Science 40 (6), 386-397. 
Hiltz, S., Johnson, K., 1989. Measuring Acceptance of Computer-mediated communication systems. Journal of the American Society for Information Science 40 (6), 386-397.

Hughes, D., Deery, R., Lovatt, A., 2002. A critical ethnographic approach to facilitating cultural shift in midwifery. Midwifery 18, 43-52.

Kaplan, B., 2000. Culture counts: how institutional values affect computer use. MD Computing 1, 23-26.

Kirkham, M., 1999. The culture of midwifery in the National Health Service in England. Journal of Advanced Nursing 32 (2), 465-472.

Lacja, S., 1999. NHS Information Strategy - A Dramatically Better Prospect For The Future. The British Journal of Health Care Computing and Information Management 16 (1), 282-284.

Larsen, K., Adamsen, L., Bjerregaard, L., Madsen, J., 2002. There is no gap 'per se' between theory and practice: Research Knowledge and clinical practice are developed in different context and follow their own logic. Nursing Outlook 50 (5), 204-212.

Lave, J., Wenger, E., 1993. Situated learning: legitimate peripheral participation. Cambridge University Press, New York.

Littler, C., Weist, A., 1998. Front-line evidence-based midwifery. RCM Midwives Journal 1 (9), 282-284.

McAdam, A., Reid, A., 2001. SME and large organisation perceptions of knowledge management: comparisons and contrasts. Journal of Knowledge Management 5 (3), 231-241.

McCormack, B., Kitson, A., Harvey, G., Rycroft-Malone, J., Tichen, A., Seers, K., 2002. Getting evidence into practice: the meaning of context. Journal of Advanced Nursing 38 (1), 94-104.

Murray, P., 2003. E-learning and its benefits for developing nursing practice. ITIN 15 (2), $18-24$.

Murray, P., 1996. Nurses computer mediated communications on nursenet. A case study. Comput Nurse 14 (4), 227-234.

Nauert, L., 1997. Bedside computers and quality documentation. Nursing Management 24 (7), 106.

Pereira, J., Bruera, E., Quan, H., 2001. Palliative care on the net: an online survey of health care professionals. Journal of Palliative Care 17 (41-45).

Quintas, P., 2002. Managing knowledge in a new century. In: Little, S., Quintas, P., Ray, T. (Eds.), Managing Knowledge. Sage, London.

Rowland, H., Harris, L., 1998. Doctor Know. People Management 4 (5), 50-52.

Royle, J., Blythe, J., Dicenso, S., Boblin-Cummings, R., Deber, R., Hayward, R., 2000. Evaluation of a system for providing information resources to nurses. Health Informatics Journal 6, 100-109.

Ruberg, L.F., Moore, D., Taylor, C., 1996. Student participation, interaction and regulation in a computer mediated communication environment: A qualitative study. Journal of educational computing research 14 (3), 243-268.

Rycroft-Malone, J., Seers, K., Tichen, A., Harvey, G., Kitson, A., McCormack, B., 2004. What counts as evidence in evidence-based practice? Journal of Advanced Nursing 47 (1), 87-90.

Schon, D., 1987. Educating the reflective practitioner. Jossey-Bass, San Francisco.

Scott, P., Brooks, F., Quick, K., Macintyre, M., Rospopa, C., 2004. Assisted Electronic Communication In Nursing. In: KMI Technical Report 04-9. The Knowledge Media Institute, The Open University, Milton Keynes. 
Seeley-Brown, J., Duguid, P., 1991. Organizational learning and communities of practice: towards a unified view of working, learning and innovation. Organization Science 2, 40-57.

Spitzer, A., 1998. Moving into the information era : Does the current nursing paradigm still hold? Journal of Advanced Nursing 28 (4), 786-793.

Szulanski, G., 2000. The process of knowledge transfer: a diachronic analysis of 'stickiness'. Organizational Behaviour and Human Decision Processes 82 (1), 9-27.

Timmons, S., Tredoux, T., 2000. The doctor-nurse computer game: do established relationships of power influence the use of information technology in clinical practice? ITIN 12, 3-7.

Titchen, A., Ersser, S., 2001. Explicating, creating and validating professional craft knowledge. In: Higgs, J., Titchen, A. (Eds.), Practice knowledge and expertise in the health professions. Butterworth Heinman, Oxford.

Webster, J., Davies, J., 2003. 'Australian nurses and midwives' knowledge of computers and their attitudes to using them in their practice. Journal of Advanced Nursing 41 (2), 140-146.

Wyatt, J., 2001. Management of explicit and tacit knowledge. Journal of the Royal Society of Medicine 94 (1), 6-9. 
Table 1 - Participation in the CHD Forum

\begin{tabular}{|c|c|c|}
\hline Job Title & $\begin{array}{c}\text { Percentage of } \\
\text { messages posted } \\
\text { (Number) }\end{array}$ & $\begin{array}{l}\text { Percentage of Staff } \\
\text { (Number) }\end{array}$ \\
\hline $\begin{array}{l}\text { Newly Qualified Nurse } \\
\text { D grade }\end{array}$ & $20 \%(14)$ & $27 \%(7)$ \\
\hline $\begin{array}{l}\text { Experienced Staff Nurse } \\
\text { E grade }\end{array}$ & $21 \%(15)$ & $31 \%(8)$ \\
\hline $\begin{array}{l}\text { Senior Nurse } \\
\text { F grade }\end{array}$ & $7 \%(5)$ & $15 \%(4)$ \\
\hline $\begin{array}{l}\text { Sister/Charge Nurse } \\
\text { G grade }\end{array}$ & $48 \%(34)$ & $19 \%(5)$ \\
\hline $\begin{array}{l}\text { Nurse Specialist/Modern Matron } \\
\text { H grade }\end{array}$ & $3 \%(2)$ & $4 \%(1)$ \\
\hline $\begin{array}{l}\text { Other } \\
\text { (Anonymous) }\end{array}$ & $1 \%(1)$ & $4 \%(1)$ \\
\hline Total & $100 \%(71)$ & $100 \%(26)$ \\
\hline
\end{tabular}


Table 2 - Participation in the Older People Forum

\begin{tabular}{|c|c|c|}
\hline Job Title & $\begin{array}{c}\text { Percentage of } \\
\text { messages posted } \\
\text { (Number) }\end{array}$ & $\begin{array}{l}\text { Percentage of Staff } \\
\text { (Number) }\end{array}$ \\
\hline $\begin{array}{l}\text { Newly Qualified Nurse } \\
\text { D grade }\end{array}$ & $0 \%(0)$ & $0 \%(0)$ \\
\hline $\begin{array}{l}\text { Experienced Staff Nurse } \\
\text { E grade }\end{array}$ & $2 \%(1)$ & $8 \%(1)$ \\
\hline $\begin{array}{l}\text { Senior Nurse } \\
\text { F grade }\end{array}$ & $43 \%(23)$ & $46 \%(6)$ \\
\hline $\begin{array}{l}\text { Sister/Charge Nurse } \\
\text { G grade }\end{array}$ & $46 \%(25)$ & $30 \%(4)$ \\
\hline $\begin{array}{l}\text { Nurse Specialist/Modern Matron } \\
\text { H grade }\end{array}$ & $7 \%(4)$ & $8 \%(1)$ \\
\hline $\begin{array}{l}\text { Other } \\
\text { (Anonymous) }\end{array}$ & $2 \%(1)$ & $8 \%(1)$ \\
\hline Total & $100 \%(54)$ & $100 \%(13)$ \\
\hline
\end{tabular}


Table 3 - Participation in the Obstetric Forum

\begin{tabular}{|l|c|c|}
\hline \multicolumn{1}{|c}{ Job Title } & $\begin{array}{c}\text { Percentage of } \\
\text { messages posted } \\
\text { (Number) }\end{array}$ & $\begin{array}{c}\text { Percentage of Staff } \\
\text { (Number) }\end{array}$ \\
\hline Midwife & $51 \%(36)$ & $62 \%(18)$ \\
\hline Community Midwife & $7 \%(5)$ & $10 \%(3)$ \\
\hline Midwifery Sister & $9 \%(6)$ & $7 \%(2)$ \\
\hline Manager & $19 \%(13)$ & $7 \%(2)$ \\
\hline Other Non- Midwives & $14 \%(10)$ & $100 \%(29)$ \\
\hline Total & $100 \%(70)$ & \\
\hline
\end{tabular}


Figure 1 - Summary of information work vs. knowledge work

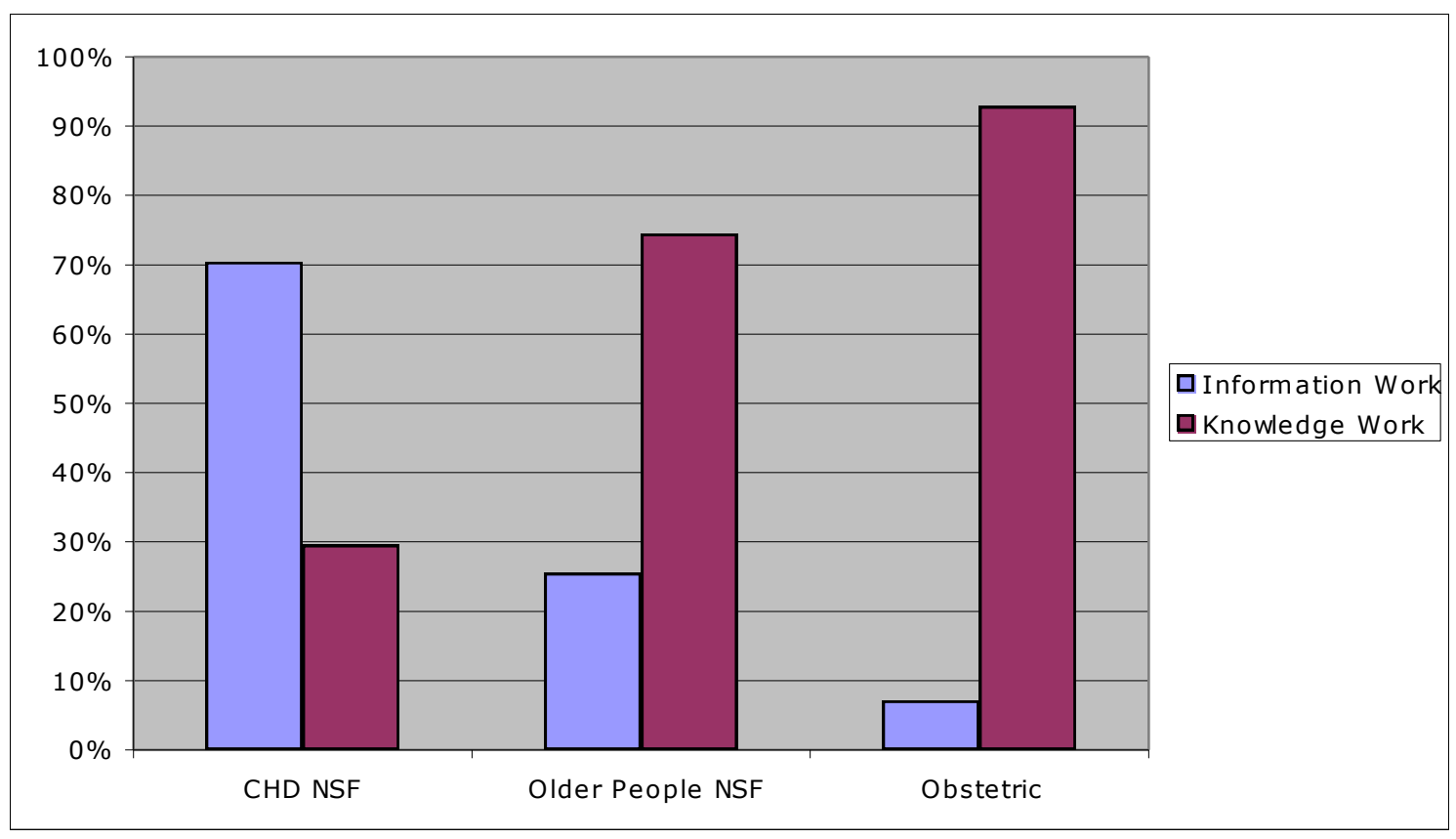


Figure 2 - Detail of Knowledge Work in 3 forums

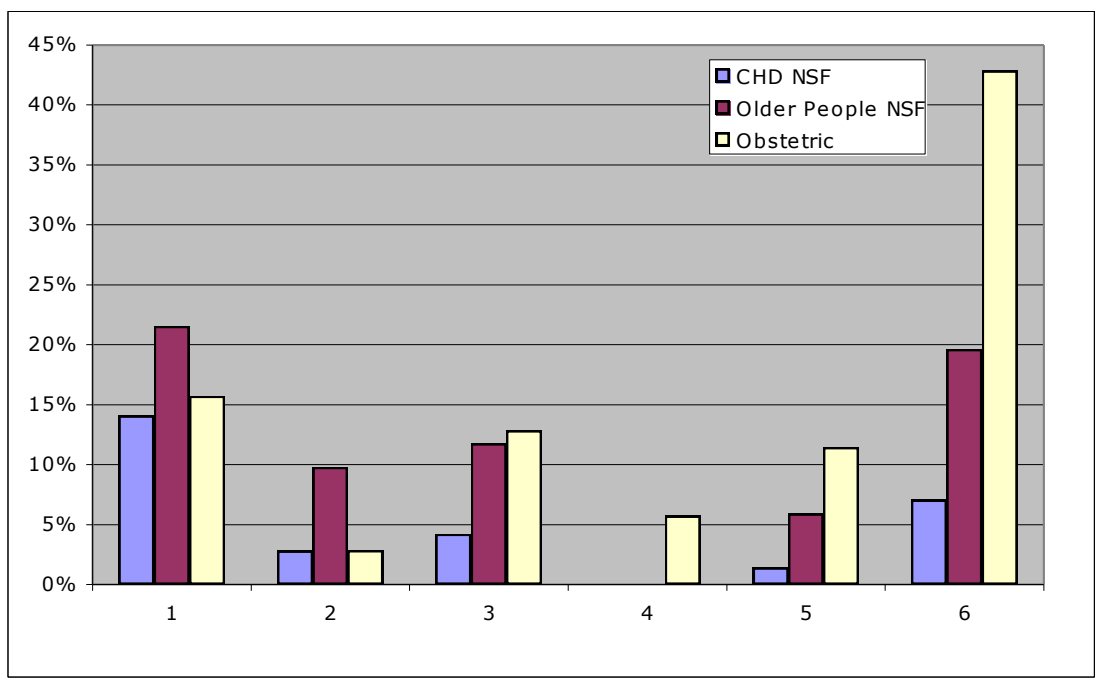

Key

1. Discursive issue raising.

2. Narrative only

3. Discursive debate

4. Tacit and evidence-base combined

5. Discursive support

6. Discursive resolution 
Figure 3 - Detail of Information Work in 3 forums

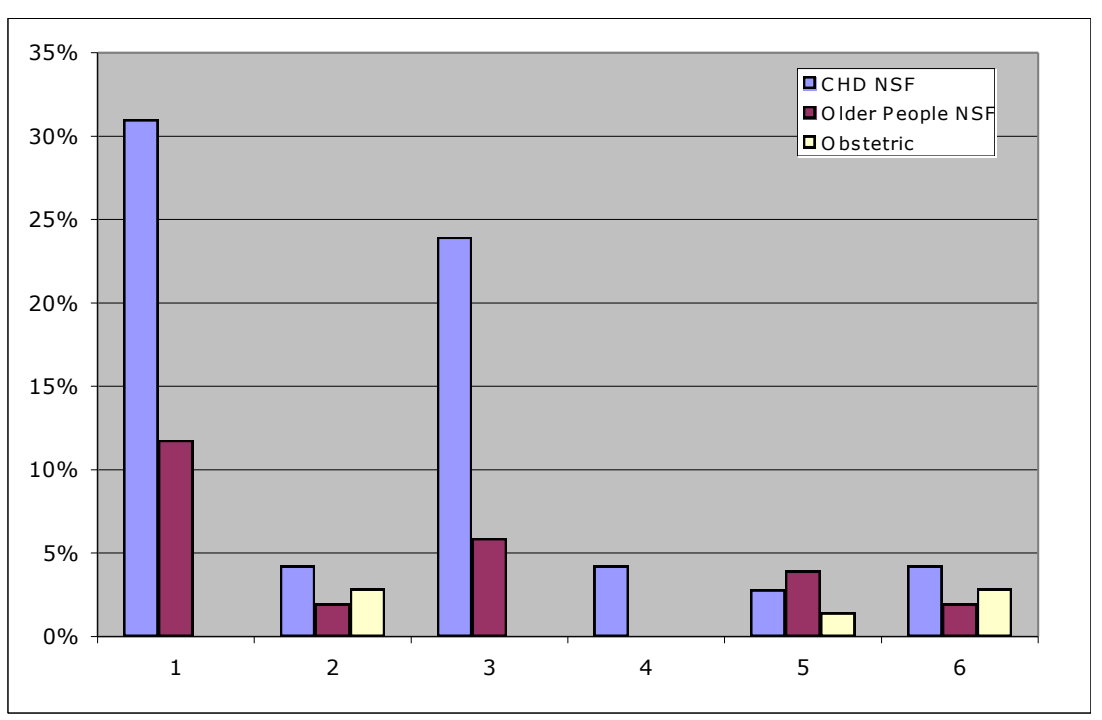

Key

1. Closed questions

2. Explicit

knowledge

response to open

question

3. Explicit

knowledge

response to

closed question

4. Explicit evidencebase

5. Information display

6. Non-discursive response 
Figure 4 - Information work in the CHD forum

\begin{tabular}{|c|c|}
\hline \multicolumn{2}{|c|}{ Example - TG-CC-19 } \\
\hline $\begin{array}{l}\text { Anne } X \\
21 \text { Feb;15.27 }\end{array}$ & $\begin{array}{l}\text { where are the policies which dictate when to give particular } \\
\text { drugs? }\end{array}$ \\
\hline $\begin{array}{l}\text { Tony } X \\
25 \text { Feb; 07:52 }\end{array}$ & $\begin{array}{l}\text { There is already a policy on CCU (April 1998) which states } \\
\text { when tPA should be used rather than streptokinase for } \\
\text { acute MI: } \\
\text { (1) for patients under } 65 \text { years with anterior MI presenting } \\
\text { within } 6 \text { hours. } \\
\text { (2) patient has had strep } 5 \text { days to } 5 \text { years ago } \\
\text { (3) patient is severely hypotensive }(<70 \mathrm{mmHg}) \\
\text { (4) patient has severe allergic disease } \\
\text { (5) patient has strep throat infection. }\end{array}$ \\
\hline $\begin{array}{l}\text { Barbara } x \\
27 \text { Feb; 08:36 }\end{array}$ & is this policy avialable in a\&e, mau and the wards? \\
\hline $\begin{array}{l}\text { Naomi X } \\
28 \text { Feb; } 11: 15\end{array}$ & $\begin{array}{l}\text { Protocols for all cardiac conditions including when to give } \\
\text { thrombpolysis are in all admitting areas } \\
\text { All doctors within medicine are given the protocols on } \\
\text { induction, with regular teaching sessions on treatment } \\
\text { If you cannot find the policies please let me know. }\end{array}$ \\
\hline
\end{tabular}


Figure 5 - Continuing discursive debate

\begin{tabular}{|l|l|}
\hline Example - TM-MF-22 & \multicolumn{1}{|c|}{ Thread-RE: Information packs } \\
\hline $\begin{array}{l}\text { Anglea } x \\
12 \text { Dec; } 15: 28\end{array}$ & $\begin{array}{l}\text { There is some excellent work done on this by the Liverpool } \\
\text { Hospitals Trust, with information themed throughout the } \\
\text { obstetric booklet - I have a copy in my office if anyone } \\
\text { wishes to view it }\end{array}$ \\
\hline $\begin{array}{l}\text { Mary } x \\
13 \text { Dec; } 23: 46\end{array}$ & $\begin{array}{l}\text { Would you be able to post a summary of it on this forum as } \\
\text { we on nights have difficulty accessing your office, we don't } \\
\text { like to search through when you are not in. What are they } \\
\text { doing differently in Liverpool? }\end{array}$ \\
\hline
\end{tabular}


Figure 6 - Failed discursive debate

\begin{tabular}{|l|l|}
\hline Example - TG-CC-19 \\
\hline Sue $x$ \\
21 May; 10:49 & The NSF states "increasing to at least 75\% the proportion of \\
& A\&E departments able to provide thrombolysis leading to \\
$75 \%$ of eligible patients receiving thrombolysis within 30 \\
minutes of hospital arrival by April 2002 and within 20 \\
minutes by April 2003" \\
Clinical performance indicators for July 2000- 30 Sept 2000 \\
A\&E 59\% RECIEVED THROMBOLYSIS <40MINS \\
CCU 100\% RECIEVED THROMBOLYSIS <40MINS \\
MAU 75\% RECIEVED THROMBOLYSIS <40MINS \\
Unacceptible delays \\
REASONS FOR DELAYS INCLUDED TRANSFERING \\
PATIENTS BEFORE THROMBOLYSIS \\
Acceptible delays \\
BP TO HIGH / LOW \\
HOWEVER THE MEAN TIME FOR ALL PATIENTS HAS \\
REMAINED UNDER 40 MINS RANGE 27MINS \\
How can we improve to meet the targets? \\
\hline
\end{tabular}




\section{Figure 7 - Example of critical reflective thinking}

\begin{tabular}{|c|c|}
\hline Example - TG-OPF-13 & Thread-RE: Age Discrimination \\
\hline $\begin{array}{l}\text { Jackie } x \\
10 \text { Aug; } 15.55\end{array}$ & $\begin{array}{l}\text { Inactive and sometimes unintentional discrimination } \\
\text { happens when older people are unable (due to confusion / } \\
\text { dementia) to articulate their needs verbally. It is easier to } \\
\text { respond to the louder, more verbal younger patient and to } \\
\text { recognise their needs than it is to the quiet elderly patient } \\
\text { whose needs may be just as valid or even more urgent. } \\
\text { > Do you feel that your area actively or inactively } \\
\text { discriminates against the older person }\end{array}$ \\
\hline $\begin{array}{l}\text { T. } x \\
14 \text { Aug; 18:03 }\end{array}$ & $\begin{array}{l}\text { Is the answer to go back to wards which specialise in the } \\
\text { care of the older person. Or is this a form of discrimination } \\
\text { in its own right. } \\
\text { Perhaps we need nurses who are able to articulate their } \\
\text { patients needs for them. Specialist nurses! Rather than } \\
\text { special wards? }\end{array}$ \\
\hline $\begin{array}{l}\text { Karen } x \\
20 \text { Aug; 16:21 }\end{array}$ & $\begin{array}{l}\text { I agree that specialist nurses are ideally the answer. Given } \\
\text { the relative unpopularity of elderly care nursing, would } \\
\text { specialist wards lead to an even bigger problem of } \\
\text { recruitment and retention than already exists in other areas } \\
\text { - thereby disadvantaging the elderly patients by good } \\
\text { intentions? Is the answer to tackle the issue of the } \\
\text { unpopularity of elderly care nursing at student level? }\end{array}$ \\
\hline
\end{tabular}


Figure 8 - Highlighting discursive support

\begin{tabular}{|l|l|}
\hline Example - TG-PSS-04 & \multicolumn{1}{l|}{ Thread - RE: Labour needs } \\
\hline $\begin{array}{ll}\text { Jenny } x \\
17 \text { Dec; 17:23 }\end{array}$ & I AGREE, WE COULD CERTANLY DO WITH MORE \\
& HOME FROM HOME ROOMS TO ENCOURAGE A \\
& NATURAL PROGRESSION THROUGH LABOUR, AND \\
& ENCOURAGE WOMEN TO MOBILISE MORE. \\
I WOULD ALSO LIKE TO SEE MORE WOMEN IN \\
DIFFERENT POSITIONS IN LABOUR, PERHAPS WE \\
COULD DO WITH MORE BEAN BAGS AND \\
MATTRESSES FOR THE FLOOR
\end{tabular}

